\title{
The Effects of Wear upon the Axial Profile of a Grinding Wheel in the Construction of Innovative Grinding Wheels for Internal Cylindrical Grinding
}

\author{
K. Nadolny and B. Słowiński \\ Department of Production Engineering, Faculty of Mechanical Engineering, Koszalin University of Technology, Racławicka 15-17, \\ 75-620 Koszalin, Poland \\ Correspondence should be addressed to K. Nadolny, krzysztof.nadolny@tu.koszalin.pl
}

Received 16 September 2010; Revised 22 February 2011; Accepted 6 June 2011

Academic Editor: J. Paulo Davim

Copyright ( $) 2011$ K. Nadolny and B. Słowiński. This is an open access article distributed under the Creative Commons Attribution License, which permits unrestricted use, distribution, and reproduction in any medium, provided the original work is properly cited.

\begin{abstract}
The article describes the effects of wear upon the axial profile of a grinding wheel in the axial cylindrical grinding processes. This mechanism was used to develop a grinding wheel with zone diversified structure made of microcrystalline sintered corundum abrasive grains and vitrifies bond. Such a grinding wheel is characterized by the conical rough grinding zone that is made by grains of a relatively large size, and a cylindrical finish grinding zone with grains of a smaller size and can be used in the singlepass grinding processes. Investigative tests conducted using newly-developed grinding wheels were described. Investigations were operated in the single-pass internal cylindrical grinding process of 100Cr6 steel. A comparison of results obtained using a zone diversified structure grinding wheel, with reference to a grinding wheel with grains of one size, were given. The analysis provides the roughness of the grinded surface, the grinding power, as well as chosen indicators of grinding efficiency. Experimental results obtained with use of a zone-diversified grinding wheel, built from relatively cheap grains of microcrystalline sintered corundum, showed that it is possible to obtain large material removal rate $Q_{w}$ up to approximately $24 \mathrm{~mm}^{3} / \mathrm{s}$ and high quality of machined surface $(R a=0.16-0.39 \mu \mathrm{m})$.
\end{abstract}

\section{Introduction}

Grinding is a method of producing technical surfaces with great precision and fineness using tools made from thousands of little grains of a hard material (aloxite, silicon carbide) or a very hard material (diamond, cubic boron nitride), bonded appropriately [1]. The great mechanical load and high temperature in the contact area between the tool and the ground material gives rise to tribological processes (frictional, chemical, diffusion, adhesion) which causes the quick wear of the abrasive grains and as a consequence the loss of the cutting ability of the tool [1$3]$. There are a wide range of experiments underway that involve the reduction of these processes by different types of modifications to the construction of the grinding tools [25]. Most of these modifications involve the changing of parts, relating to a chosen aspect of the work, for example, a change of the abrasive material, bonding material, technology, tool structure and so forth. This paper describes the complex (system) approach to improving grinding tools-Figure 1.

Of the many issues surrounding the decision-making processes in the area of technological developments, one is particularly important and concerns how to rationally manage or how to use owned resources to get the maximum effect $E_{f w}$. This problem, for the tested grinding operation, can be reduced to an optimization task in the following general form: with minimal consumption of resources $N$ should be received at the intended degree of project implementation $W$ :

$$
E_{f w}=\frac{W}{N}, \quad N \longrightarrow \min , W=\text { const },
$$

where $E_{f w}$ is the efficiency, expressed by grinding operation costs $K, N$ the wear of the grinding wheel, which is a function 


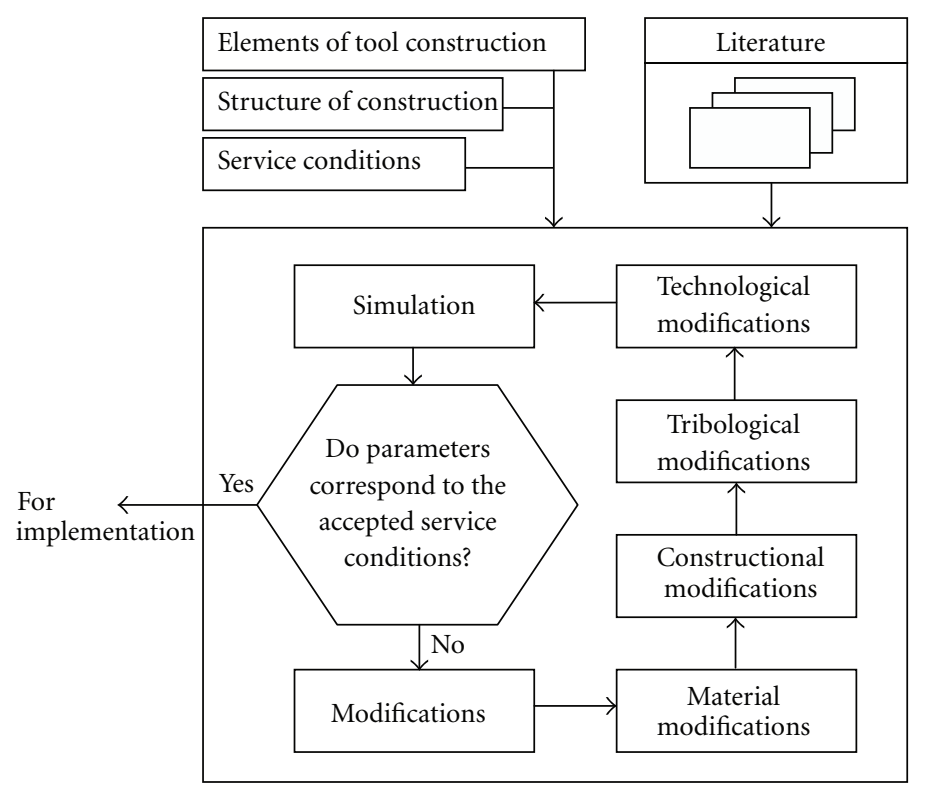

FIGURE 1: Procedures for designing modernized grinding tools with specified types of modifications.

of operation time $t$, and $W$ constraints (the set of essential terms of the quality of grounded surface).

More specifically this task can be shown by writing: find the minimum grinding cost function $K(t)$ for time values $t$, contained in a set of feasible solutions $T$, while maintaining the assumed parameters of the grinded surface quality, where $K(t)$ is an objective function (optimization criterion).

To solve this task, a system approach was used. It focuses on the investigation of optimal solutions through a logical analysis of the structure of the system. The next steps of this analysis are given in a concise form in Figure 1, and its results are in the form of the final product (grinding wheel meets the objective function and restrictions).

To obtain the final result it was required to make significant changes in the analyzed operation system. These changes were written as a modification:

(1) material modification: the replacement of expensive CBN abrasive grains with cheaper SG grains;

(2) design modification: the replacement of a uniform grinding wheel with a zone-diversified grinding wheel;

(3) tribological modification: different sizes of abrasive grains in different zones of the grinding wheel;

(4) technology modification: the replacement of the reciprocating multipass grinding method with the singlepass grinding method;

(5) simulation on the mathematical model: in order to determine the processing parameters that meet the constraints posed by the machined surface quality.

\section{Wear Characteristic of the Grinding Wheel Axial Profile}

One of the possible ways to observe the wear of the axial profile of the grinding wheel is the formation of a conical

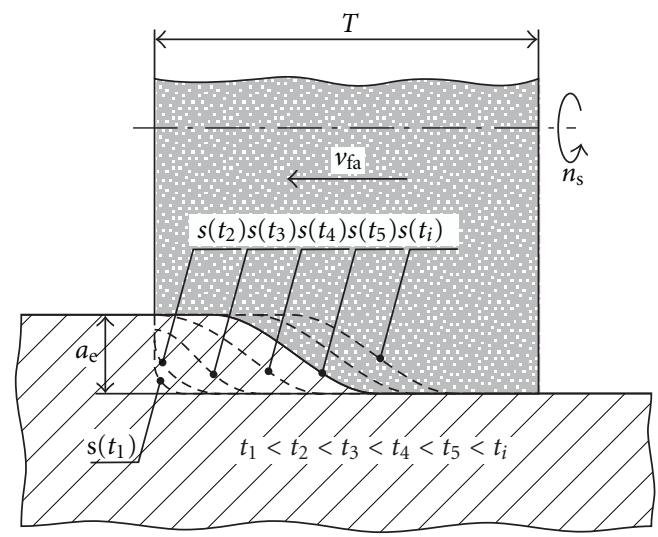

FIGURE 2: The effects of wear upon the axial profile of a grinding wheel [6].

zone. During the grinding, the grinding wheel cuts into the material of the workpiece with one of its front edges. The simple wear model assumes that there is a formation of diagonal wear in the attacking part. In reality, the shape is curvilinear (Figure 2) and mostly depends on the depth of the grinding $a_{e}$, the speed of the axial table feed $v_{\mathrm{fa}}$, as well as the characteristics of the grinding wheel.

There are two phases to the wear described. Firstly, in a short time, a slant is formed on the front part of the grinding wheel active surface (GWAS) along its entire width $s\left(t_{1}-t_{3}\right)$; next, the grinding wheel evenly wears itself during the work causing shifting of the diagonal area along the depth of the grinding wheel $s\left(t_{4}-t_{i}\right)$ [6].

The described wear of the grinding wheel mechanism causes the taking over of the main work of removing the allowance from the conic zone; however, the cylindrical zone removes the unevenness from the ground surface. This means that with the increase of wear of the grinding wheel, 


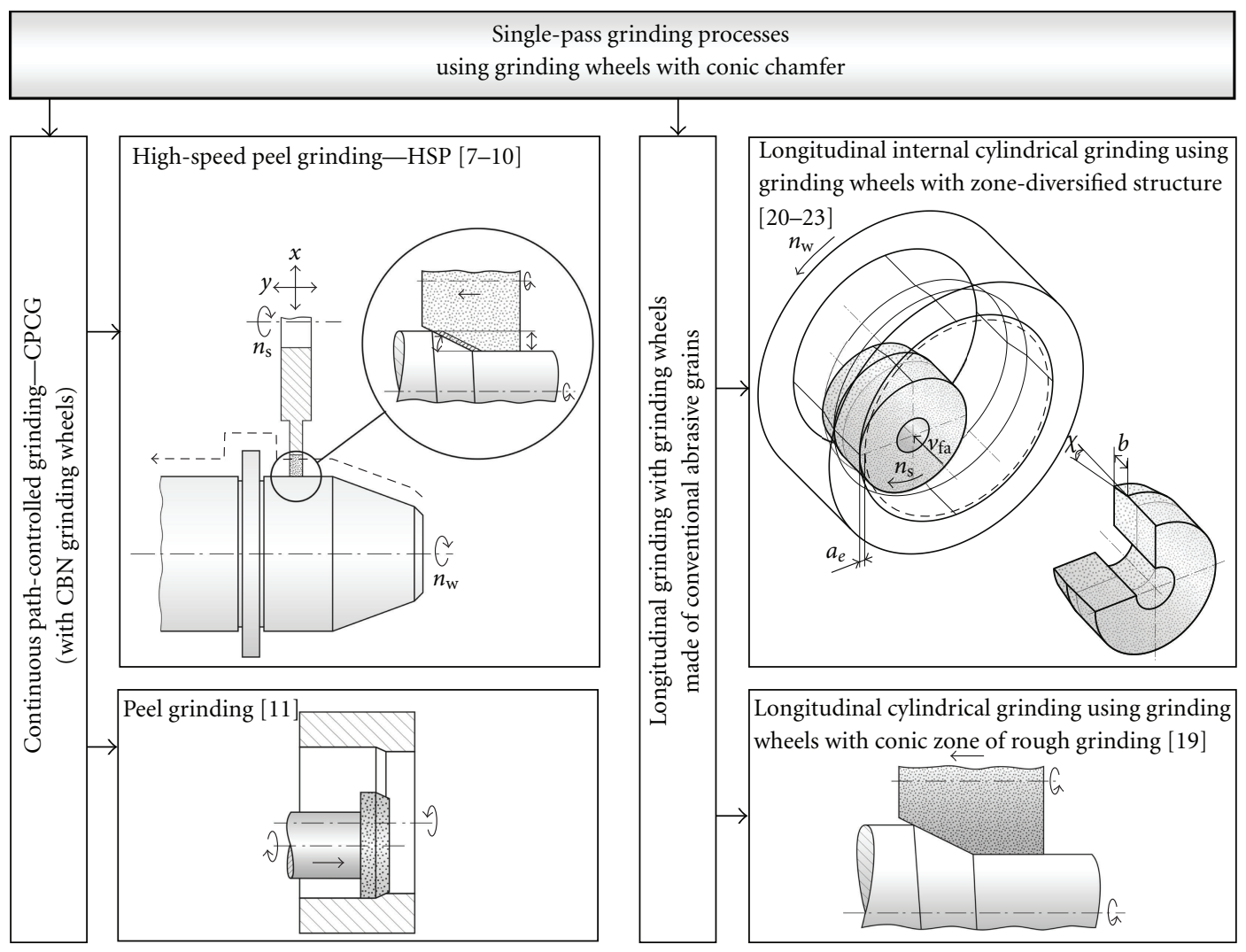

FIGURE 3: Single-pass grinding processes carried out using grinding wheels with conic chamfer.

the smoothing area decreases, which has a negative effect on the quality of the workpiece surface.

Such a characteristic of the profile wear of the GWAS was used to work on a grinding wheel with a conic chamfer. Such grinding wheels are intentionally characterized by their chamfer with an adequately chosen angle $\chi$ and width $b$. The forming of a conic chamfer allows for the even distribution of large machining allowance on a larger GWAS, which also means a greater number of active grains. These types of grinding wheels are mainly used in the processes of grinding where large machining allowances are removed, for example, in the processes of single-pass grinding.

\section{Single-Pass Grinding Processes}

As already presented, the essence of single-pass grinding is the complete removal of machining allowance in one passing of the grinding wheel, whilst maintaining the desired quality of the surface of the workpiece $[4,7-18]$. The most commonly met single-pass processes should include the continuous path-controlled grinding [7-10], internal cylindrical peel grinding [11], grinding with reduced contact with the grinding wheel (the Quickpoint method) [12-14], as well as deep grinding with creep feed [15-18].

In such processes grinding wheels with super-hard grains are mainly used, like Cubic Boron Nitride (CBN) grains. In addition, the methods of single-pass grinding with the use of conventional grinding wheels are also developed [19-23].
For the better use of the potential of the grinding tool, there is often a conic chamfer shaped in the attacking part of the grinding wheel. The processes of single-pass grinding using grinding wheels with a conic chamfer are presented in Figure 3.

In the first group of single-pass grinding processes (Peel grinding, High-Speed Peel grinding), CBN grinding wheels with conic chamfers are used. Such grinding wheels are narrow (usually a few millimeters) with a diameter of 300$400 \mathrm{~mm}$. They are characterized by division into two basic zones: a rough grinding zone 2 to $5 \mathrm{~mm}$ wide and a finish machining zone $2 \mathrm{~mm}$ wide [7-10]. In the second group are processes conducted with use of grinding wheels made of conventional abrasive materials such as alumina oxide abrasive grains or microcrystalline sintered corundum. In such cases, grinding wheels are much wider $(20-50 \mathrm{~mm})$ [19-23].

\section{Grinding Wheels with a Zone-Diversified Structure}

Grinding wheels with a zone-diversified structure [20-23] are characterized by the rough grinding zone that is made by grains of a relatively large size, whereas the cylindrical finish grinding zone has grains of a smaller size. The role of the rough grinding zone is to remove the allowance; however, the role of the finish grinding zone is to spark out and smooth the surface. That is why, in the rough grinding zone, there 


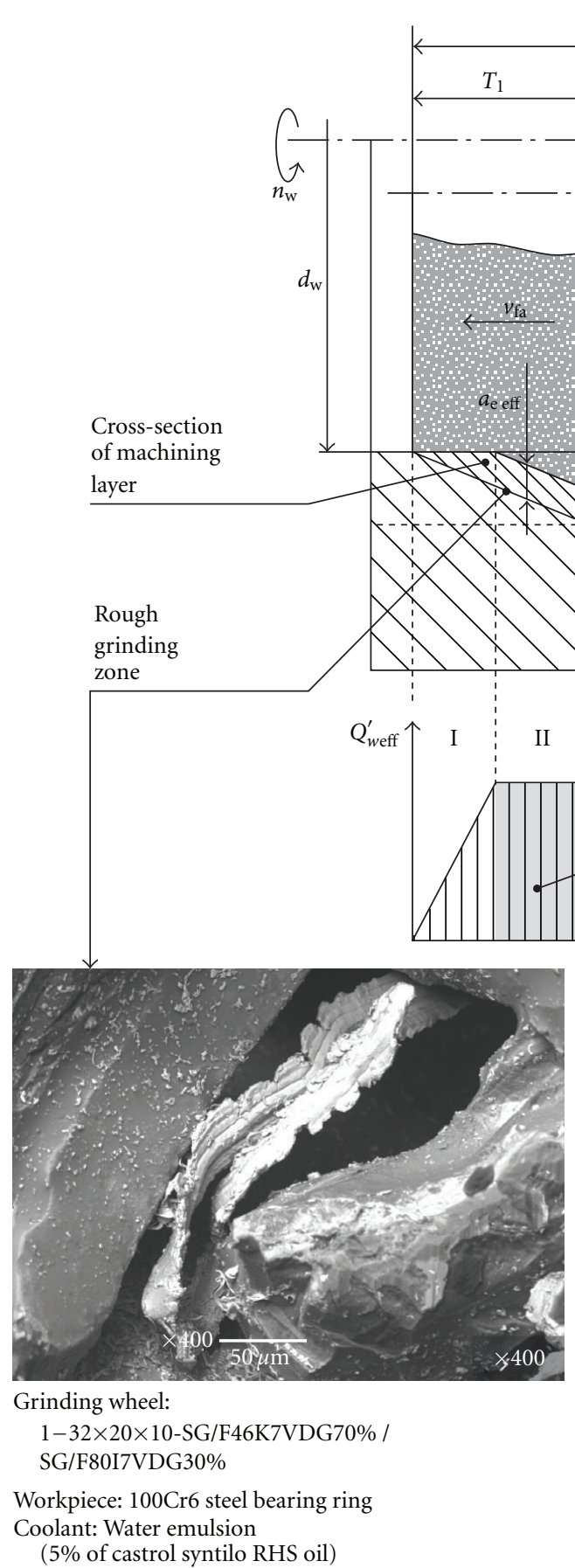

(b)

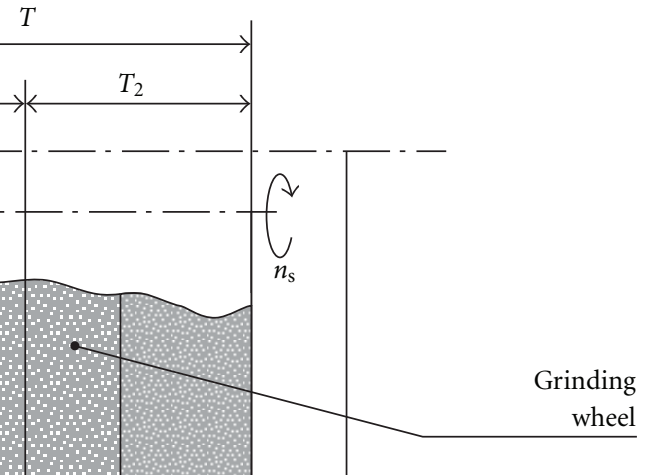




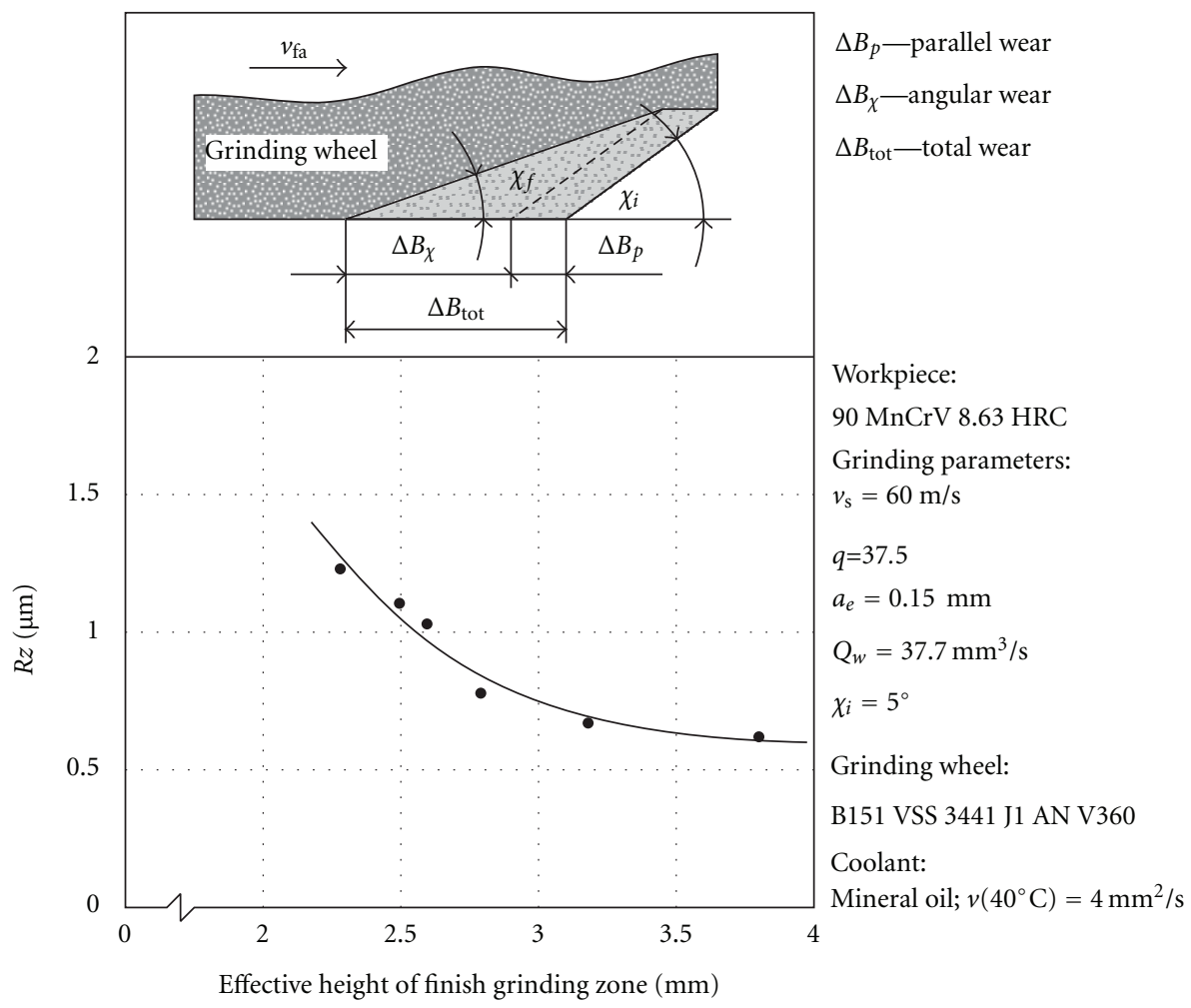

FIGURE 5: Forms of the grinding wheel active surface edge wear occurring in the course of single-pass grinding using grinding wheels with a conic chamfer [11].

the decreasing of the number of active grains, which in turn increases the roughness of the worked surface. The angular wear, however, causes the decrease of the angle of the conic chamfer which means the extension of the rough grinding zone. In such a case there is an increase in the number of active grains in the worked zone, which leads to the decrease of their individual load and decrease in the intensity of their wear [11]. Therefore, the setting of the appropriate proportions of the width of the rough grinding zone and the finish grinding zone has an important influence on the intensity of the wear of the grinding wheel as well as on the results of the grinding.

Additional benefits of the exploitation of the grinding wheels may be provided by the use of different types of grains in the rough and finish grinding zones. In the rough grinding zone, these should be grains made from monocrystals or poly-crystals, with very sharp vertexes, mechanical resilience with good cutting ability, and the aptitude to self sharpen. In the finish grinding zone, however, the grains should have microcrystalline structure with large numbers of microvertexes which can carry out the process of microsparking out and smoothing machined surfaces [23].

Prototypes of such grinding wheels were mainly made with grains from cubic boron nitride $(\mathrm{CBN})$, with ceramic binding. The progress of tests of the described processes and the optimization of the structure of the grinding wheel has allowed for the replacing of CBN grains with much cheaper grains of microcrystalline sintered corundum SG [23]. The primary purpose of replacing CBN grinding wheels with SG grinding wheels is this economic aspect. The price of the CBN grains is about 10 times higher than the price of SG grains. CBN grinding wheels are also more difficult to shape and dress which is significant when conic chamfers need to be formed.

\section{Research Tests}

The carrying out of a wide range of simulation research tests helped determine the most beneficial conditions for implementing the processes of single-pass internal cylindrical grinding with new grinding wheels. The structure of the zone-diversified grinding wheel was also optimized taking into account the type and size of the abrasive grains in each of the zones, the whole height of the grinding wheel $T$, the involvement of the height of particular parts $\left(T_{1} / T_{2}\right)$, as well as the breadth $b$ and angle of the conic chamfer $\chi$ [23].

Presented below are the test results of the influence of depth of grinding $a_{e}$ and speed of axial feed $v_{\mathrm{fa}}$ (which directly dictates the efficiency of grinding removal $Q_{w}$ ) on the progress and results of processes of the internal cylindrical single-pass grinding, with zonediversified structure grinding wheels.

5.1. Grinding Wheels. In tests a zone-diversified grinding wheel was used with the most beneficial characteristics (marked 46/80-30\%)—Figure 6(a), as well as a reference grinding wheel made completely from SG grains size 46 (marked 46-100\%)—Figure 6(b). 


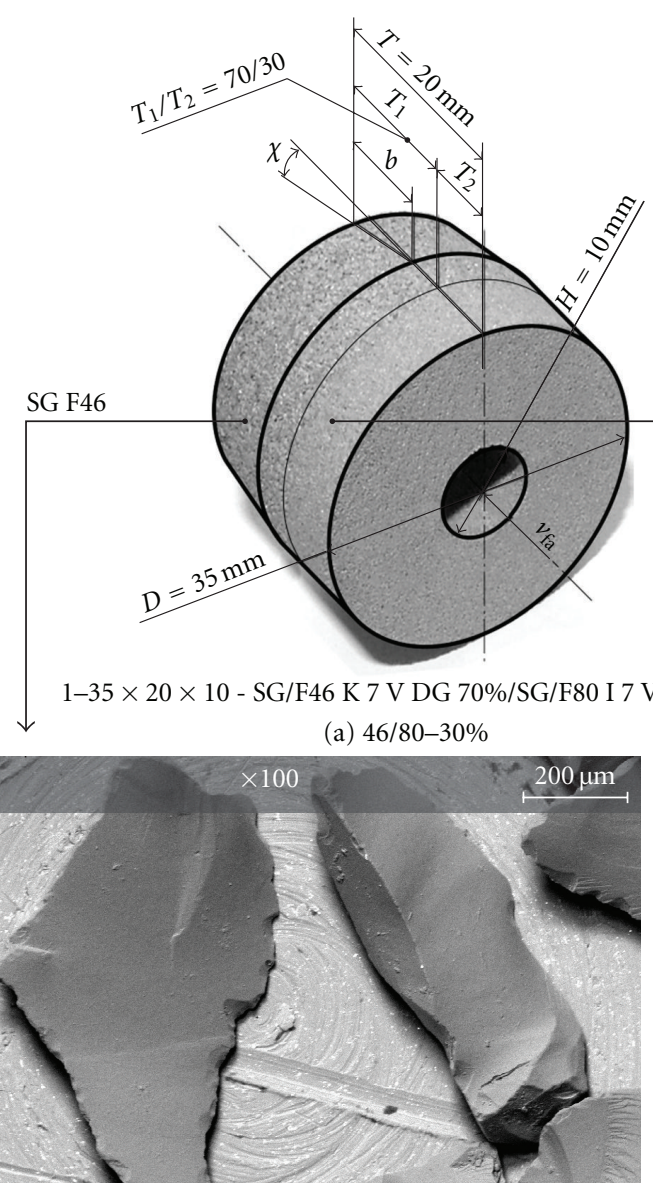

(c)

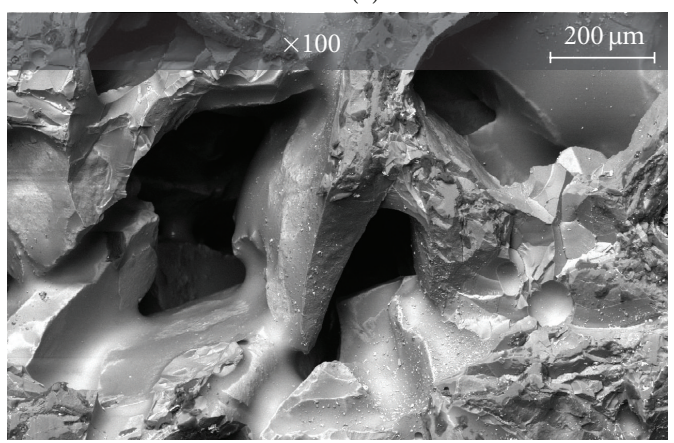

(e)

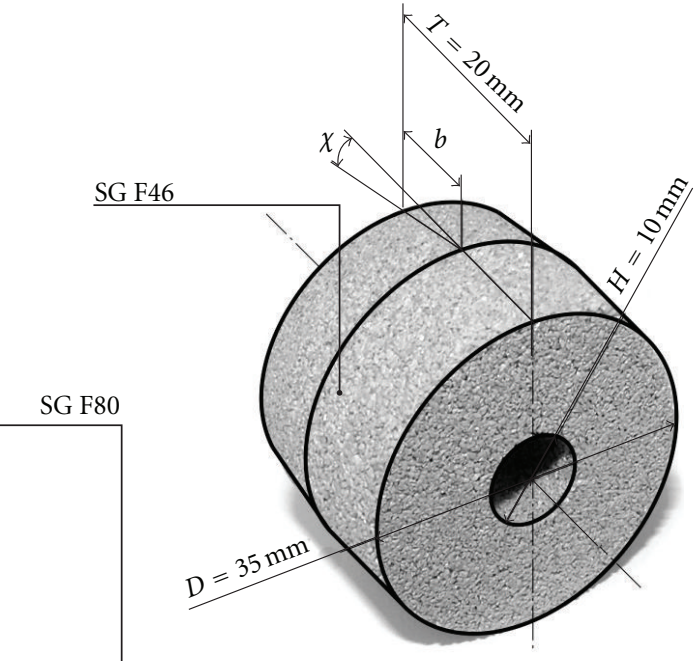

$1-35 \times 20 \times 10-$ SG/F46 K 7 V DG $100 \%$

(b) $46-100 \%$

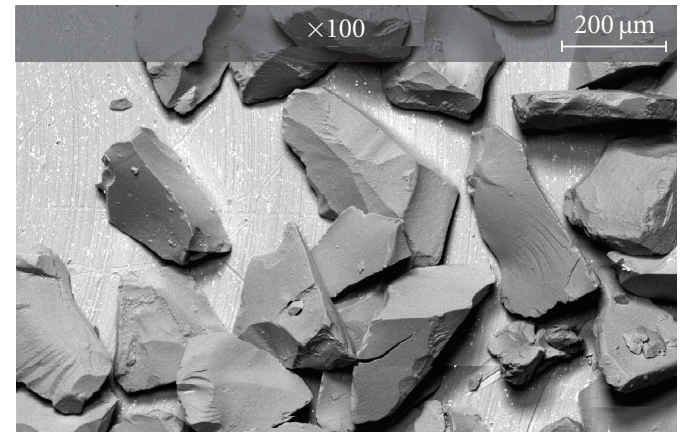

(d)

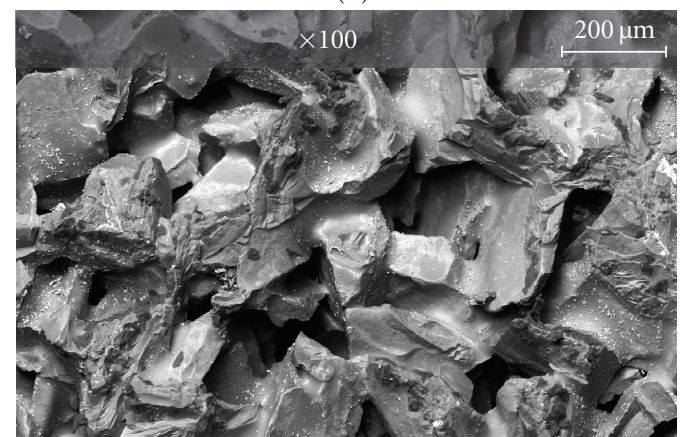

(f)

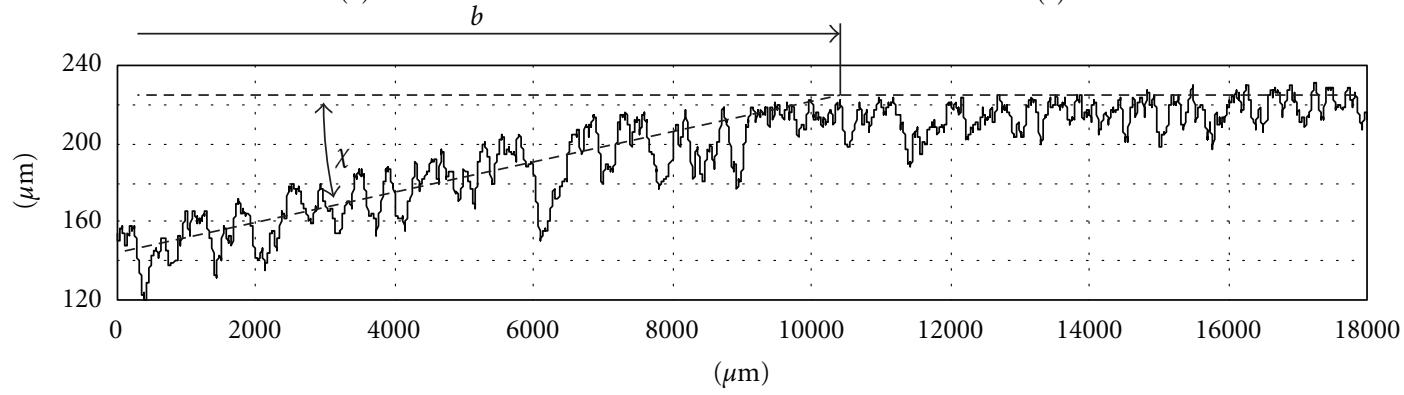

(g)

FIGURE 6: Grinding wheel with zone-diversified structure made of microcrystalline sintered corundum abrasive grains SG size 46 and 80 : (a) construction scheme of grinding wheel with zone-diversified structure; (b) construction scheme of reference grinding wheel built of SG grains size 46; (c) microscopic view of SG grains size 46; (d) microscopic view of SG grains size 80; (e) microscopic view of the GWAS in conical zone of rough grinding; (f) microscopic view of the GWAS in cylindrical zone of finish grinding; (g) microgeometric axial profile of the grinding wheel active surface with an exposed conic chamfer. 
In these grinding wheels, a special glass-crystalline bond was used. It distinguishes itself by the mechanism of the fatigue cracking of binder bridges, which is comparable to the fatigue crumble of microcrystalline vertexes of SG abrasive grains because these are materials of similar brittleness [24]. Such properties allow for the ability of the grinding wheel to self-sharpen.

5.2. Test Results. In Tables 1 and 2, nonlinear 2nd degree models are presented as well as their multidimensional correlated coefficients $R$, assigned on the basis of the implementation of the three-level experiment plan. Tests were carried out on the influence of change of the working engagement $a_{e}$ and speed of the axial table feed $v_{\mathrm{fa}}$ on the arithmetic average deviation of the roughness of the workpiece $R a$ (Table 1 ) as well as the grinding power gain $\Delta P$ (Table 2).

The differences in the obtained values of the arithmetic average deviation of the roughness of the surface workpiece $R a$ point out that the use of a grinding wheel with a zonediversified structure allows for more than $40 \%$ decrease in the value of this parameter (Figure 8). The difference is especially visible for smaller values of the axial feed. This is as a result of the large number of cutting microvertexes in the finish grinding zone made from grains of size 80 . The surface generated from grains of size 46 found in the conical part of such a grinding wheel remains ultimately finished and sharpened by a large number of edges found on the surface of the cylindrical zone. As a result, the less efficient loss is shaped by the surface characterized by a nearly two times lower value of the parameter $R a$ when compared to the surface grinding by a grinding wheel completely made from grains 46.

Along with the rise of material removal rate, the differences in achieving a roughness of the workpiece surface visibly declined. Along with the increase of $a_{e}$ and $v_{\mathrm{fa}}$, the waste efficiency of grinding visibly rises. The load of the abrasive grains increases, which in difficult conditions, despite the zone-diversified structure, generates an increasing surface roughness, where this increase is most intensive as compared to grinding wheels $46-100 \%$. The introduction of a finish grinding zone of height $30 \%$, made from grains of size 80 , causes a limited participation of the very porous surface of the grinding wheel made from grains 46 . The remaining GWAS parts are unable to equally effectively perform the rough grinding, because it was used for smoothing and sparking out the surfaces. With values of higher waste efficiency, as a result of increased deformation of the spring construction, the conic chamfer removes the smaller part of the whole depth of grinding leaving more material to be ground by the cylindrical part.

Comparing the results of the grinding power gain $\Delta P$ obtained from two tested grinding wheels, it may be said that, in the whole range of change of $v_{\mathrm{fa}}$, the beneficial values were obtained by grinding wheels with a zone-diversified structure (Figure 7). Increased need of grinding power of 46$100 \%$ is a result of the increased sections of layers cut by individual grains. The active surface of this grinding wheel is

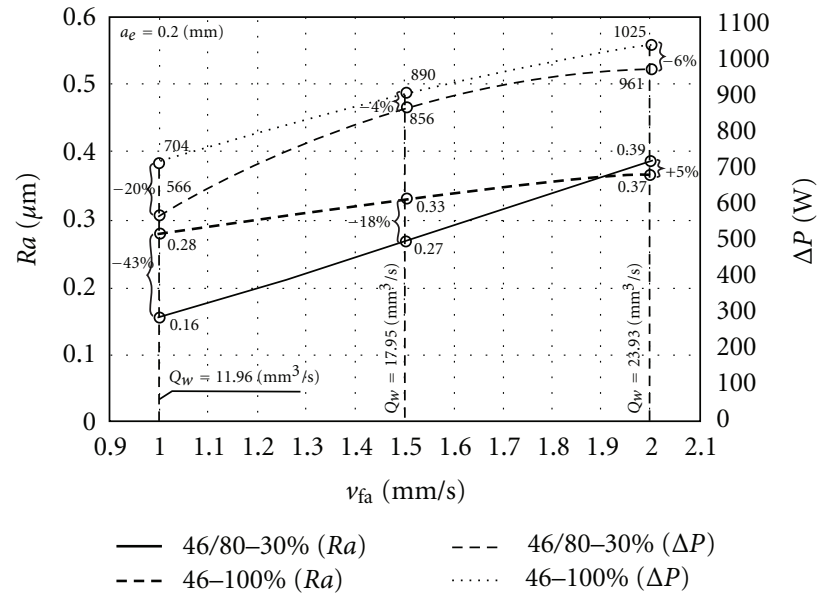

FIGURE 7: Comparison of changes in the arithmetic mean roughness $R a$ and grinding power gain $\Delta P$ measured after grinding using $46 / 80-30 \%$ and $46-100 \%$ grinding wheels as a functionof the feed speed $v_{\mathrm{fa}}$ at the working engagement $a_{e}=0.20 \mathrm{~mm}$.

characterized by a relatively small number of cutting vertexes, which are put through increased loads during the process of machining, which in effect causes an increase of the grinding power.

Experimental tests allowed the capture of a series of microscopic images of the GWAS after grinding (Figure 8). The analysis of these images shows that, in the applied grinding conditions, the phenomenon of abrasive wear of the SG abrasive grains vertexes dominates on the GWAS (Figure $8(a)$ ). To a small extent, there is also adhesive wear manifested by the sticking of workpiece chips to the abrasive grains vertexes (Figure 8(b)).

A relatively large load in the rough grinding zone of the GWAS locally caused fatigue wear and cracking of vitrified bond bridges (Figure 8(c)). Also of interest are the spherical chips which are formed in microareas where abrasive grains make contact with the workpiece material (Figure 8(d)). The spherical form of such chips is caused by a momentary heating up of microchips to a temperature exceeding the melting point. These chips then cool down, creating empty spherical forms. The occurrence of this type of chips demonstrates the difficult conditions and inadequate cooling of the grinding zone.

5.3. Grinding Efficiency. In addition, the efficiency of the implementation of the described process with the two subject grinding wheels was tested. Among the many grinding judgement criteria described in the literature, four basic indicators were selected:

(i) quality indicator: $\mathrm{IN}_{Q}=R a[\mu m]$;

(ii) indicator of the course of grinding:

(i) grinding power $\mathrm{IN}_{\mathrm{C} 1}=P_{c}[W]$;

(ii) appropriate grinding power $\mathrm{IN}_{\mathrm{C} 2}=P_{s c}^{\prime}=P_{c} /$ $Q_{w}\left[W \cdot s / \mathrm{mm}^{3}\right]$ 
TABLE 1: Breakdown of mathematical models describing the changes in the surface roughness of a workpiece $R a$ as a function of the working engagement $a_{e}$ and axial table feed speed $v_{\mathrm{fa}}[22]$.
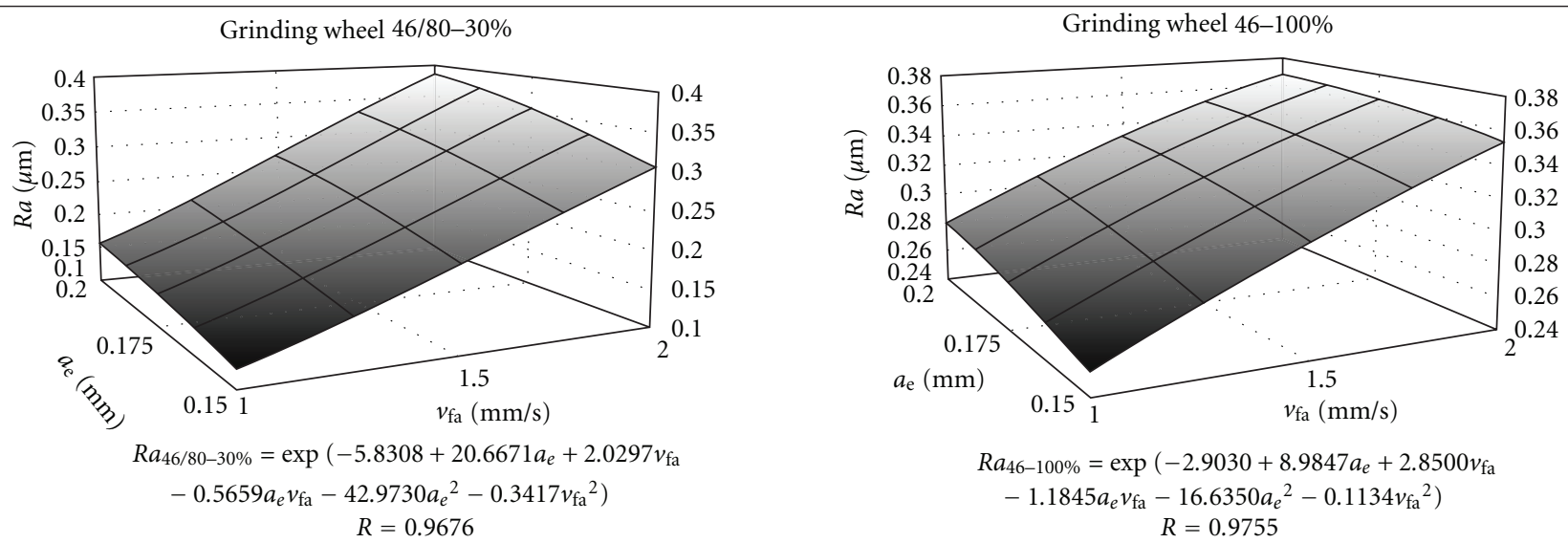

\begin{tabular}{lllll}
\hline$v_{s}=60[\mathrm{~m} / \mathrm{s}]$ & $v_{w}=0.75[\mathrm{~m} / \mathrm{s}]$ & $a_{e}=0.15-0.20[\mathrm{~mm}]$ & $Q_{c}=5.0[\mathrm{~L} / \mathrm{min}]$ & $\chi=0.60-0.91\left[{ }^{\circ}\right]$ \\
$n_{s}=35300-39200[\mathrm{rpm}]$ & $n_{w}=341[\mathrm{rpm}]$ & $v_{\mathrm{fa}}=1.0-2.0[\mathrm{~mm} / \mathrm{s}]$ & $q=80$ & $b=12.6-14.4[\mathrm{~mm}]$
\end{tabular}

TABLE 2: Breakdown of mathematical models describing the grinding power gain $\Delta P$ as a function of the working engagement $a_{e}$ and axial table feed speed $v_{\text {fa }}[22]$.
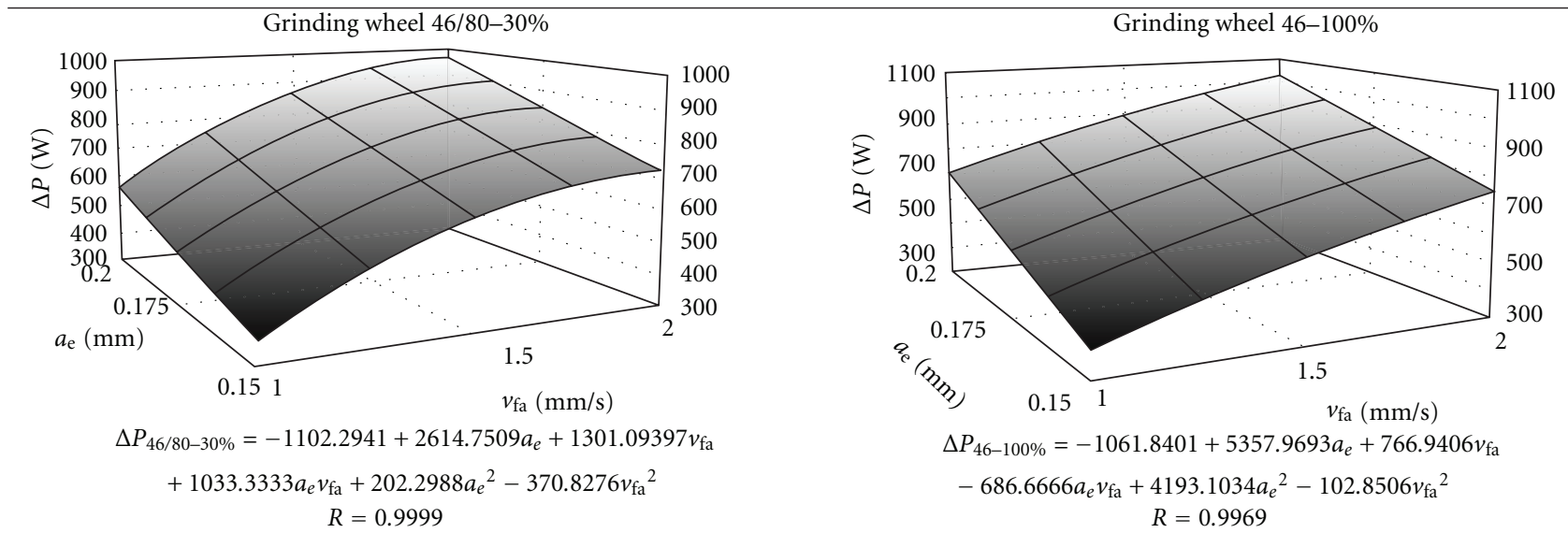

\begin{tabular}{lllll}
\hline$v_{s}=60[\mathrm{~m} / \mathrm{s}]$ & $v_{w}=0.75[\mathrm{~m} / \mathrm{s}]$ & $a_{e}=0.15-0.20[\mathrm{~mm}]$ & $Q_{C}=5.0[\mathrm{~L} / \mathrm{min}]$ & $\chi=0.60-0.91\left[^{\circ}\right]$ \\
$n_{s}=35300-39200[\mathrm{rpm}]$ & $n_{w}=341[\mathrm{rpm}]$ & $v_{\mathrm{fa}}=1.0-2.0[\mathrm{~mm} / \mathrm{s}]$ & $q=80$ & $b=12.6-14.4[\mathrm{~mm}]$ \\
\hline
\end{tabular}

(iii) synthetic indicator:

(i)

$$
\mathrm{IN}_{\mathrm{S}}=K=\frac{Q_{w}}{P_{c} \cdot R a}\left[\frac{\mathrm{mm}^{2}}{\mathrm{~W} \cdot \mathrm{s}}\right]
$$

The stated indicators include, in the most, normalized criteria $\left(R a, Q_{w}, P_{c}, P_{s c}^{\prime}\right)$ popularly used to judge the efficiency achieved in the grinding process. It is accepted that the grinding power is equal to the registered electrical power gain of the grinding wheel spindle $P_{c}=\Delta P$. The synthetic indicator $K$ allows for a complete judgement of the process through the taking into account of the waste efficiency, registered power, and roughness of the surface after grinding. In effect this allows for the comparison of efficiency with energy outputs and the quality achieved on the outer layers of the machined workpiece [8].

Percentage value breakdown of the grinding performance evaluation criteria for grinding wheels with the best results (46/80-30\%) with regard to grinding wheel $46-100 \%$ is presented in Figure 9.

This means that the processes used in single-pass internal cylindrical grinding with grinding wheels with a zonediversified structure allowed for the significant increase in efficiency of the process through the decrease of the roughness of the surface of the machined workpiece and the increase of the waste effectiveness. 


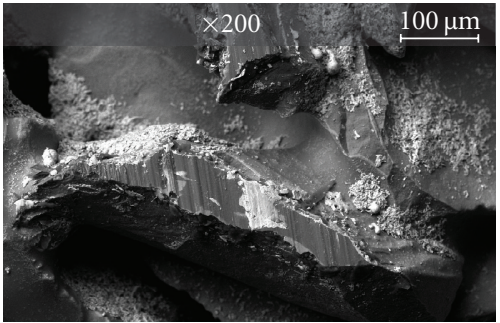

(a)

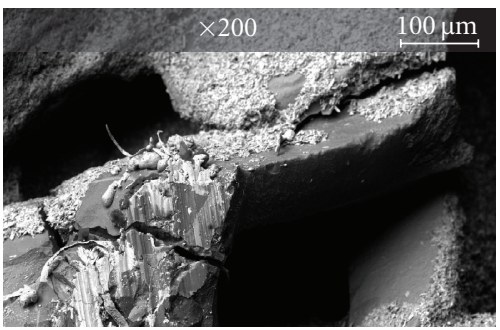

(c)

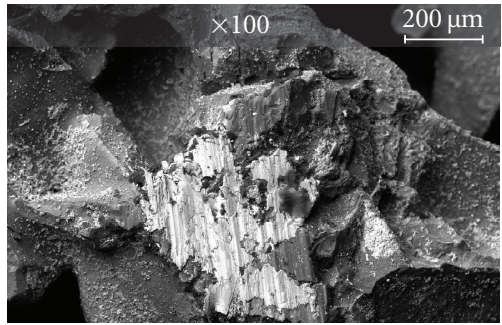

(b)

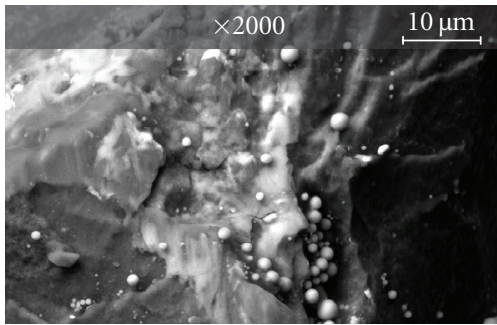

(d)

FIGURE 8: Microscopic view of the GWAS after grinding: (a) wear land of SG abrasive grain; (b) smear of workpiece chips on the abrasive grain vertex; (c) crack of the vitrified bond bridge; (d) spherical chips of machined material on the abrasive grain vertex.

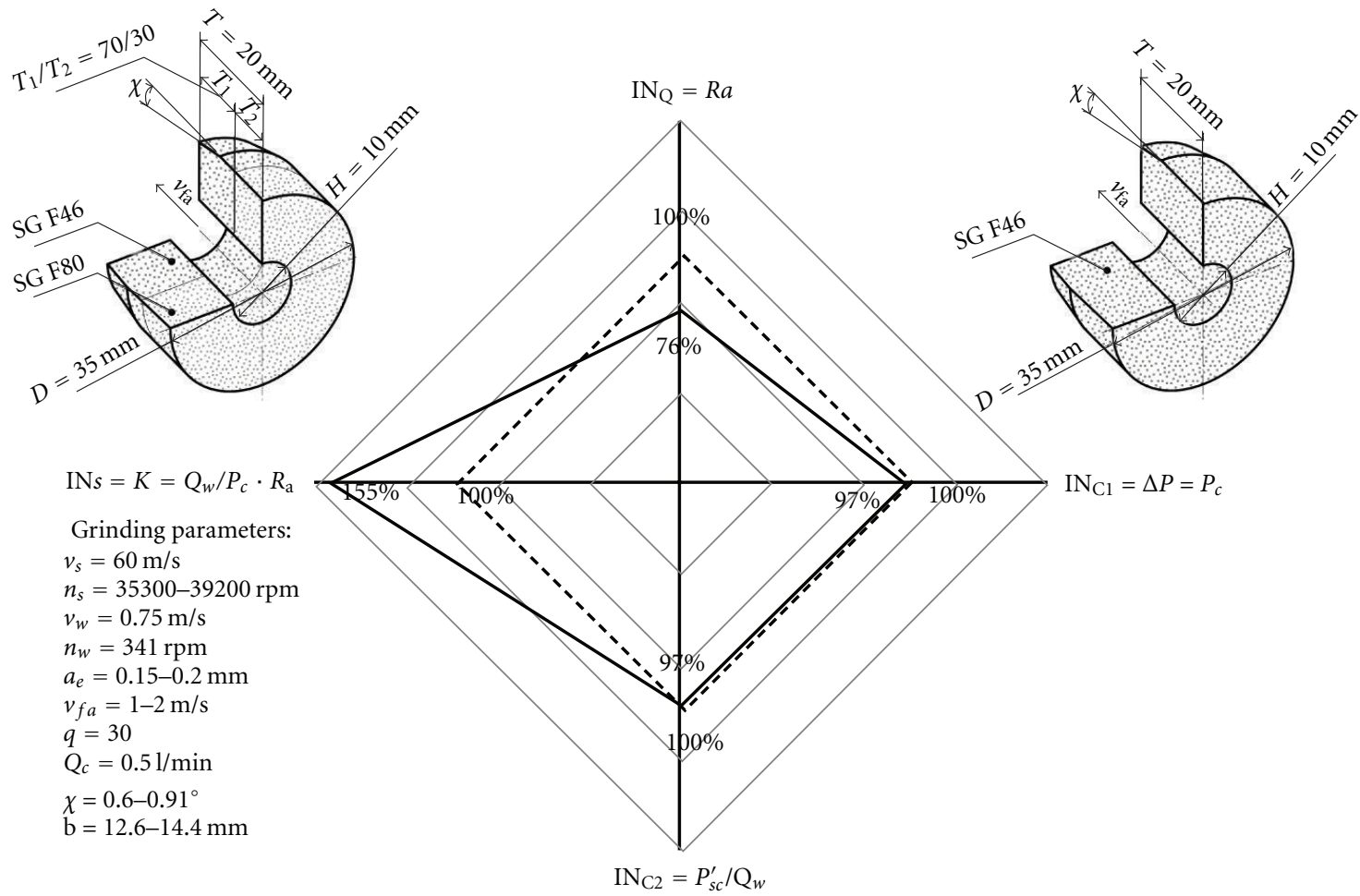

- 46/80-30\%

- - $\quad 46-100 \%$

FIGURE 9: Percentage value setting up of the grinding efficiency evaluation criteria for a grinding wheel of zone-diversified structure (46/80$30 \%$ ) with reference to a $46-100 \%$ grinding wheel. 


\section{Conclusions}

During the grinding process, many of the wear processes affect the GWAS, such as abrasive wear, adhesive wear, thermal wear and fatigue wear. All these phenomena occur at the microscale of contacts between the components of the GWAS (abrasive grains, bond) and the machined material. Their intensity depends primarily on the grinding parameters. In the case of single-pass grinding, it depends on machining allowance $a_{e}$ and axial table feed speed $v_{\mathrm{fa}}$. These two parameters affect the wear at the macroscale, which reveals a change in the axial profile of the grinding wheel.

A naturally formed axial profile of the grinding wheel was the basis for the development of a grinding wheel with conic chamfer. The developments of this concept lead to the creation of a grinding wheel with a zone-diversified structure. In such tools, it is necessary to optimize the type and size of the abrasive grains in each zone as well as the whole height of the grinding wheel $T$, height participation of the particular parts $\left(T_{1} / T_{2}\right)$, as well as the breadth $b$ and angle of the conic chamfer $\chi$.

The use of such grinding wheels built from relatively cheap grains of microcrystalline sintered corundum SG allowed for the achievement of effective grinding at the level $Q_{w} \approx 24 \mathrm{~mm}^{3} / \mathrm{s}$. At the same time, beneficial values of parameters describing the roughness of the worked surfaces were attained, which depending on the process parameters changed in the range: $R a=0.16-0.39 \mu \mathrm{m}$.

The tests carried out pointed to the significant increase in the efficiency of the process of single-pass internal cylindrical grinding achieved by the use of grinding wheels with a zonediversified structure, in relation to grinding wheels entirely constructed from grains of one size.

\section{Nomenclature}

GWAS: Grinding wheel active surface

$a_{e}$ : Working engagement, $\mathrm{mm}$

$a_{e \text { eff }}$ : Efficient working engagement, $\mathrm{mm}$

$a_{e \text { tot }}$ : Total working engagement, $\mathrm{mm}$

$a_{f}: \quad$ Feed engagement, $\mathrm{mm}$

$b$ : $\quad$ Conic chamfer breadth, $\mathrm{mm}$

$d_{s}$ : $\quad$ Grinding wheel diameter, $\mathrm{mm}$

$d_{w}: \quad$ Workpiece diameter, mm

D: $\quad$ Grinding wheel outside diameter, $\mathrm{mm}$

$H$ : $\quad$ Grinding wheel inside diameter, $\mathrm{mm}$

$K$ : $\quad$ Synthetic indicator of the grinding efficiency, $\mathrm{mm}^{2} / \mathrm{W} \cdot \mathrm{s}$

$n_{s}$ : Grinding wheel rotational frequency, $\mathrm{rpm}$

$n_{w}$ : Workpiece rotational frequency, rpm

$P_{c}$ : $\quad$ Cutting (grinding) power, $\mathrm{W}$

$P_{c}^{\prime}$ : $\quad$ Proper cutting power, $\mathrm{W} \cdot \mathrm{s} / \mathrm{mm}^{3}$

$q: \quad$ Speed ratio $\left(v_{s} / v_{w}\right)$

$Q_{c}: \quad$ Coolant flow rate, $\mathrm{L} / \mathrm{min}$

$Q_{w}: \quad$ Material removal rate, $\mathrm{mm}^{3} / \mathrm{s}$

$Q_{w \text { eff }}^{\prime}:$ Effective proper material removal rate, $\mathrm{mm}^{2} / \mathrm{s}$

$R: \quad$ Multidimensional correlated coefficient of mathematical model
$R a: \quad$ Arithmetic mean deviation of the assessed profile, $\mu \mathrm{m}$

$R z$ : Maximum height of the profile within a sampling length, $\mu \mathrm{m}$

$s(t)$ : Shape of the grinding wheel active surface in axial direction after grinding time $t$

t: $\quad$ Grinding time, s

$T$ : Grinding wheel total height in axial direction, $\mathrm{mm}$

$T_{1}$ : Grinding wheel rough grinding zone height in axial direction, $\mathrm{mm}$

$T_{2}$ : Grinding wheel finish grinding zone height in axial direction, $\mathrm{mm}$

$v_{\text {fa }}: \quad$ Axial table feed speed, $\mathrm{mm} / \mathrm{s}$

$v_{s}$ : Grinding wheel peripheral speed, $\mathrm{m} / \mathrm{s}$

$v_{w}$ : Workpiece peripheral speed, $\mathrm{m} / \mathrm{s}$

$\chi$ : $\quad$ Conic chamfer angle, ${ }^{\circ}$

$\chi_{f}: \quad$ Final conic chamfer angle, ${ }^{\circ}$

$\chi_{i}$ : $\quad$ Initial conic chamfer angle, ${ }^{\circ}$

$\Delta B_{p}$ : Conic chamfer parallel wear, $\mathrm{mm}$

$\Delta B_{\text {tot }}$ : Conic chamfer total wear, $\mathrm{mm}$

$\Delta B_{\chi}$ : Conic chamfer angular wear, ${ }^{\circ}$

$\Delta P: \quad$ Increase of grinding wheel spindle current power, W.

\section{References}

[1] W. B. Rowe, Principles of Modern Grinding Technology, William Andrew Applied Science Publishers, Burligton, Vt, USA, 2009.

[2] I. D. Marinescu, W. B. Rowe, B. Dimitrov, and I. Inasaki, Tribology of Abrasive Machining Processes, William Andrew, Norwich, UK, 2004.

[3] M. J. Jackson, "Microscale wear of vitrified abrasive materials," Journal of Materials Science, vol. 39, no. 6, pp. 2131-2143, 2004.

[4] J. Webster and M. Tricard, "Innovations in abrasive products for precision grinding," Annals of the Cooperative Institutional Research Program, vol. 53, no. 2, pp. 597-617, 2004.

[5] H. K. Tönshoff, B. Karpuschewski, and T. Mandrysch, "Grinding process achievements and their consequences on machine tools challenges and opportunities," Annals of the Cooperative Institutional Research Program, vol. 47, no. 2, pp. 651-668, 1998.

[6] J. Plichta, Foundations of Grinding Process Using Grinding Wheels With Microcrystalline Grains of the Cubic Boron Nitride With Vitrified Bond, Monographs of Mechanical Department no. 58, University's Publishers of Koszalin University of Technology, Koszalin, Poland, 1996.

[7] F. Klocke, G. Hegener, and L. Deacu, "Hochleistungs-aussenrund-formschleifen. Innovatives fertigungsverfahren vereint hohe flexibilität und produktivität," Zeitschrift für wirtschaftlichen Fabrikbetrieb, vol. 91, no. 4, pp. 164-167, 1996.

[8] F. Klocke and G. Hegener, "Schnell, gut und flexibel: hochleistungs-aussenrund-formschleifen," Individual Differences Research, vol. 33, no. 2, pp. 153-160, 1999.

[9] P. Lüetjens and H. Mushardt, "Grinding out hardened parts," American Machinist, vol. 148, no. 3, pp. 52-59, 2004.

[10] P. Lütjens, "Hard turning or grinding - which is the more economical alternative?" Industrial Diamond Review, vol. 61, no. 588 , pp. 22-26, 2001. 
[11] K. Weinert, M. Finke, D. Kötter et al., "Wirtschaftliche alternative zum hartdrehen. Innenrund-schälschleifen steigert flexibilität beim schleifen von futterteilen," Maschinenmarkt, vol. 109, no. 48, pp. 44-47, 2003.

[12] E. Junker, Verfahren und Vorrichtung zum Hochgeschwindigkeits-Profilschleifen von Rotations-Symmetrischen Werkstücken, Europäisches Patent, Nr. 0176654, 1985.

[13] F. Klocke and C. Bücker, "Quickpoint-Schleifen: baustein einer flexiblen produktion. Komplettbearbeiten in nur einer aufspannung," Industrie-Anzeiger, vol. 118, no. 43-44, pp. 4849, 1996.

[14] K. Mücke, "Quickpoint-Schleifmaschine mit wendbarer Spindel. Umspannen des Werkstücks erübrigt sich," IndustrieAnzeiger, vol. 122, no. 42-43, p. 51, 2000.

[15] M. Excell, "Grinding process creeps forward," Metalworking Production, vol. 139, no. 10, pp. 67-70, 1995.

[16] C. Guo, M. Campomanes, D. McIntosh, C. Becze, and S. Malkin, "Model-based monitoring and control of continuous dress creep-feed form grinding," Annals of the Cooperative Institutional Research Program, vol. 53, no. 1, pp. 263-266, 2004.

[17] S. Salmon, "Creep-feed grinding is surprisingly versatile," Manufacturing Engineering, vol. 133, no. 5, pp. 59-64, 2004.

[18] Sunarto and Y. Ichida, "Creep feed profile grinding of Nibased superalloys with ultrafine-polycrystalline cBN abrasive grits," Precision Engineering, vol. 25, no. 4, pp. 274-283, 2001.

[19] T. Nakajima, K. Okamura, and Y. Uno, “Traverse grinding techniques for improving both productivity and surface finish," in Proceedings of the International Grinding Conference, Fontana, Calif, USA, Mr 84-534, August 1984.

[20] D. Herman, J. Plichta, and K. Nadolny, "New ceramic abrasive tools for rough and finishing grinding in one pass," Materials Science Forum, vol. 526, pp. 163-168, 2006.

[21] B. Słowiński and K. Nadolny, "Effective manufacturing method for automated inside diameter grinding," Journal of Advanced Mechanical Design, Systems, and Manufacturing, vol. 1, no. 4, pp. 472-480, 2007.

[22] K. Nadolny, J. Plichta, D. Herman, and B. Słowiński, "Singlepass grinding - an effective manufacturing method for finishing," in Proceedings of the 19th International Conference on Systems Engineering (ICSEng 2008), pp. 236-241, Las Vegas, Nev, USA, August 2008.

[23] K. Nadolny and J. Plichta, Single-Pass Internal Grinding Using Grinding Wheels with Zone-Diversified Structure, University's Publishers of Koszalin University of Technology, Koszalin, Poland, 2008.

[24] D. Herman and J. Markul, "Influence of microstructures of binder and abrasive grain on selected operational properties of ceramic grinding wheels made of alumina," International Journal of Machine Tools and Manufacture, vol. 44, no. 5, pp. 511-522, 2004. 

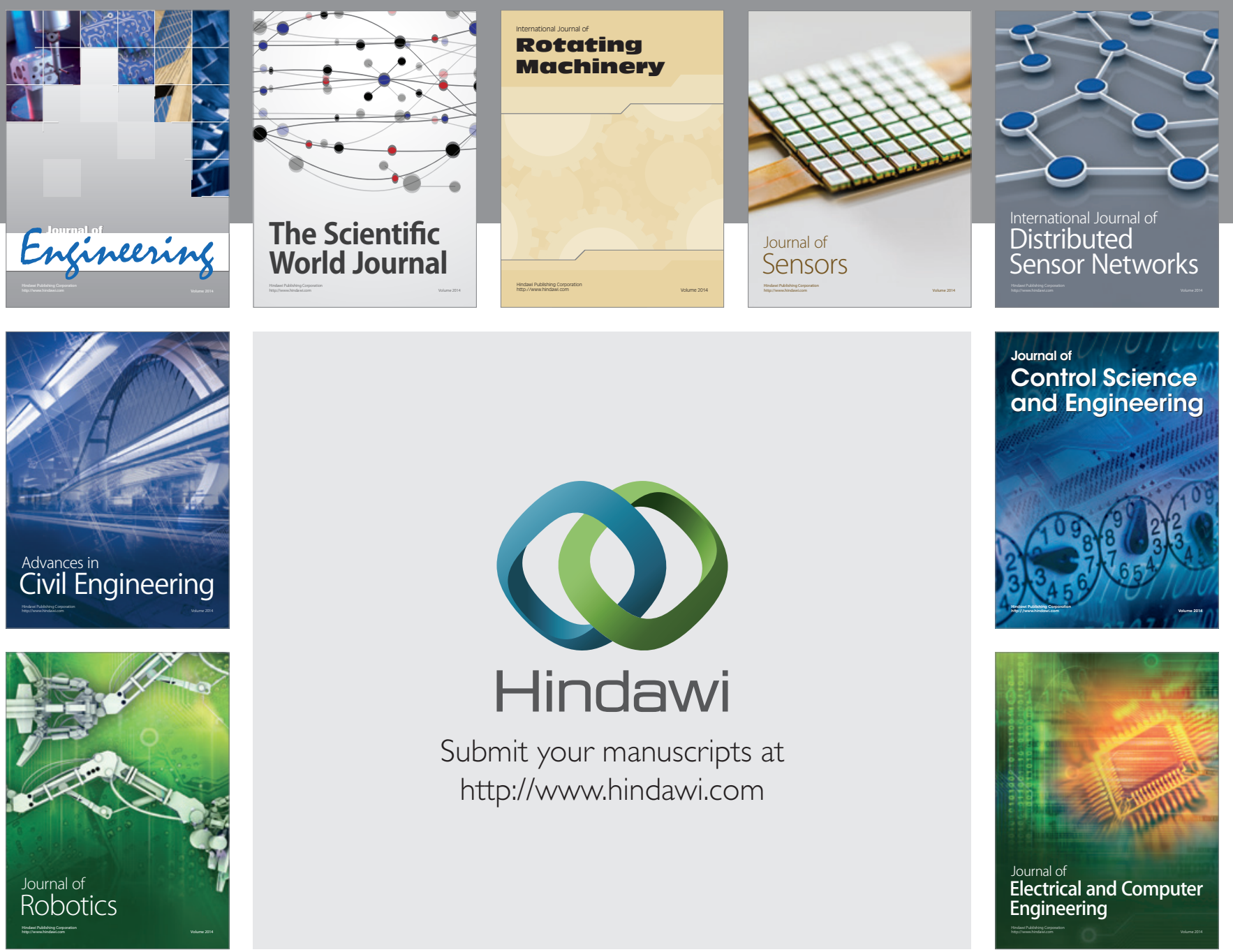

Submit your manuscripts at

http://www.hindawi.com
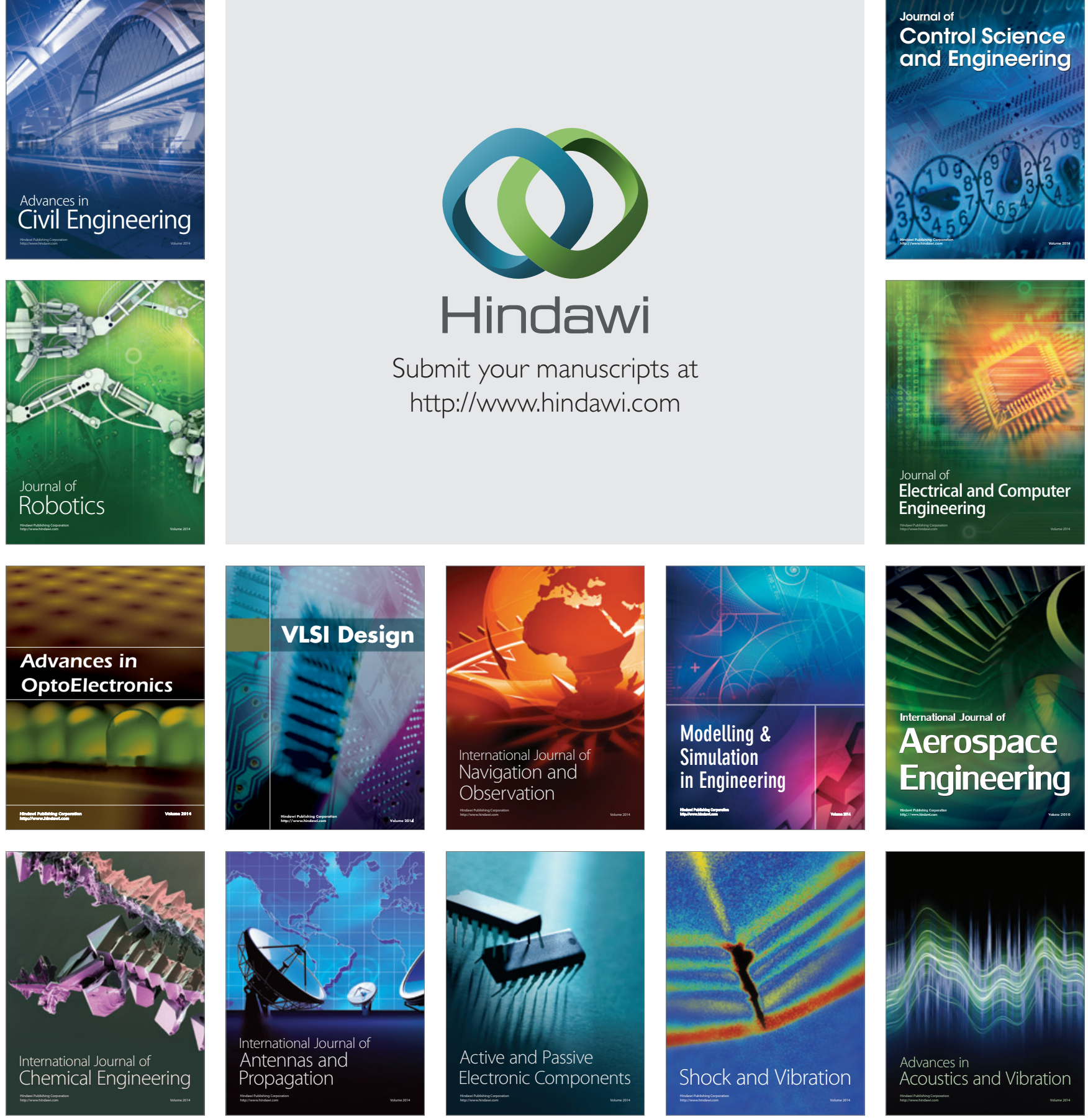